\title{
Molecular Characterization of Saffron-Potential Candidates for Crop Improvement
}

\author{
Javid Iqbal MIR ${ }^{1}$, Nazeer AHMED ${ }^{2}$, Mudasir Hafiz KHAN²*, \\ Taseem Ahmad MOKHDOMI ${ }^{1}$, Sajad Hussian WANI ${ }^{1}$, \\ Shoiab BUKHARI ${ }^{1}$, Asif AMIN ${ }^{1}$, Raies Ahmad QADRI ${ }^{1}$ \\ IUniversity of Kashmir, Srinagar,JÆK, 190006, India; javidiqbal123@rediffmail.com; raies@kashmiruniversity.ac.in \\ ${ }^{2}$ Central Institute of Temperate Horticulture, Srinagar,J\&K, 190007, India; dircithsgr@icar.org.in; me_drkhan@rediffmail.com (*correspondingauthor)
}

\begin{abstract}
In this study, thirty one (31) morphologically distinct selections of saffron crop were used for molecular characterization. Molecular characterization was done through SSR, ISSR and RAPD markers. RAPD and ISSR markers showed significant variation; however, SSR markers did not reveal any variation between the selected clones. The Jaccard's similarity coefficient ranged from 0.94 to 1.00 with an average of 0.98 among all 31 selections used. Minimum similarity value (0.94) was observed between CITH-S-107 and PAM-S-116 selections. The study provides sufficient knowledge to identify clones with better stigma characteristics for further crop improvement programs.
\end{abstract}

Keywords: Crocus sativus, genetic relationship, ISSR, molecular characterization, RAPD, SSR

\section{Introduction}

Crocus sativus L. is an autumn-flowering geophyte extensively grown in the Mediterranean basin and Near East since the Late Bronze Age (Negbi, 1999). Saffron, the dried red stigmas of C. sativus, has been used as flavouring and colouring agent since then and is currently considered the world's most expensive spice. The major components of saffron are the apocarotenoids cis- and trans-crocins, picrocrocin ( $\beta$-Dglucopyranoside of hydroxyl- $\beta$-cyclocitral) and its degradation product, the odour-active safranal (Kanakis et al., 2004).

Many studies have demonstrated that the genotypic diversity of C. sativus is extremely low (Alavi Kia et al., 2008; Rubio-Moraga et al., 2009). This limited genetic diversity in saffron is attributed to its asexual propagation, followed by successive selection during breeding efforts (Alavi Kia et al., 2008). Most of the researchers reveal that saffron is monomorphic in nature by using RAPD, SSR and ISSR markers. But still some researchers (Qadri et al., 2012) believe that RAPD markers can be used for identifying the variation within these monomorphic genotypes. PCR-based approaches are in demand because of their simplicity and also because they have shown promise in crop improvement of a large number of crops. Genetic diversity and relationships among species or populations are important topics in genetics and plant breeding. Since saffron is generally monomorphic at morphological level, there is an urgent need to identify the variation at molecular level which can be further exploited for improvement of this crop. Even though qualitative traits of saffron are indeed influenced by sowing time (Gresta et al., 2008) and environmental conditions (Siracusa et al., 2012), only few and fragmentary information correlating genetic and biochemical traits is available to date. The discovery of genetic differences in saffron would mean a new way for its improvement, and eventually the possibility to link some particular genetic traits with morphological and biochemical features. Therefore, in order to explore the variability of morphological and qualitative traits among selected saffron clones, molecular evaluation, both at genomic and expression level, was done to identify saffron clones with higher variability in respect to improved quality.

\section{Material and methods}

\section{Plantmaterial}

Thirty one (31) different saffron clones representing the core collection for saffron germplasm conservation were used in the study. These clones were collected from Central Institute of Temperate Horticulture, Rangreth, Srinagar (J \& K) and maintained at the Research Farm of said institution. Stigmas were collected from September to November 2011. Freshly cut stigmas were quickly immersed in liquid nitrogen and then stored at $-80^{\circ} \mathrm{C}$ for RNA isolation.

\section{Molecular characterization \\ DNA extraction}

DNA was extracted from $300 \mathrm{mg}$ of leaf material using a modified Doyle and Doyle method (Doyle and Doyle, 1987). Leaf material was grounded to a fine powder in liquid nitrogen and placed in a microcentrifuge tube with $2 \mathrm{~mL}$ of extraction buffer (2\% CTAB, 100 mM Tris-HCl pH 8.0, 20 mM EDTA and $1.4 \mathrm{M} \mathrm{NaCl}$ ) plus $40 \mu \mathrm{l}$ of 2-mercaptoethanol. Following incubation at $65^{\circ} \mathrm{C}$ for $30 \mathrm{~min}, 1.4 \mathrm{~mL}$ of chloroform:isoamyl 
82

alcohol (24:1) was added, mixed and centrifuged at 8,000 rpm for $30 \mathrm{~min}$; the supernatant was transferred to a new tube and then repeated three times. DNA was precipitated with isopropanol ( $2 / 3$ volume of supernatant), then centrifuged at $8,000 \mathrm{rpm}$ for $30 \mathrm{~min}$, after which the supernatant was discarded and the pellet washed in 70\% ethanol containing 10 $\mathrm{mM}$ ammonium acetate, for $20 \mathrm{~min}$. The pellet was dissolved in $100 \mu \mathrm{L}$ of TE buffer $(10 \mathrm{mM}$ Tris- $\mathrm{HCl} \mathrm{pH} 7.4,1 \mathrm{mM}$ EDTA) and the DNA was re-precipitated with 1/2 volume of ammonium acetate $3 \mathrm{M}$ and 2.5 volumes of ethanol. After centrifuging at $8,000 \mathrm{rpm}$ for $30 \mathrm{~min}$, the pellet was redissolved in TE buffer. The extracted DNA was quantified with a spectrophotometer and diluted to $30 \mathrm{ng} / \mu \mathrm{L}$ in TE. The DNA was stored at $-20^{\circ} \mathrm{C}$ for further analyses.

\section{RAPD analysis}

Samples were screened for RAPD variation using standard 10-base 128 primers specially developed for RAPD analysis, at constant low annealing temperature $\left(34-37^{\circ} \mathrm{C}\right)$. The PCR reaction $(25 \mu \mathrm{l})$ contained the following: $1 \mathrm{x}$ reaction buffer $(20$ $\mathrm{mM}$ Tris-Cl pH 8.0, $50 \mathrm{mM} \mathrm{KCl}), 0.2 \mathrm{mM}$ dNTPs, $2 \mathrm{mM}$ $\mathrm{MgCl}_{2}, 10 \mathrm{Pm}$ primer, 1.0 Unit of Taq DNA polymerase and 25 - 50 ng genomic DNA. The DNA was amplified in a thermal cycler that was programmed as follows: initial DNA denaturation for $5 \mathrm{~min}$ at $94^{\circ} \mathrm{C} ; 45 \mathrm{cycles}$ of $60 \mathrm{sec}$ at $94^{\circ} \mathrm{C}$ (denaturation), $60 \mathrm{sec}$ at $37^{\circ} \mathrm{C}$ (annealing) and $120 \mathrm{sec}$ at 72 ${ }^{\circ} \mathrm{C}$ (extension); followed by a final extension at $72^{\circ} \mathrm{C}$ for $7 \mathrm{~min}$. All primers tested on all cultivars and markers were checked three times for reproducibility. The RAPD amplified-DNA was analyzed by electrophoresis on $2 \%$ agarose gel in a $0.5 \mathrm{x}$ TBE buffer. The gels were stained with ethidium bromide $(0.5$ $\mu \mathrm{gml}^{-}{ }^{1}$ ) and visualized under UV light.

\section{ISSR and microsatellite analyses}

DNA from individual plant of each saffron accession was screened with 31 pairs of SSR and 50 ISSR primers. The PCR reaction $(25 \mu \mathrm{l})$ contained the following: $1 \mathrm{x}$ reaction buffer (20 mM Tris- $\mathrm{Cl} \mathrm{pH} \mathrm{8.0,} 50 \mathrm{mM} \mathrm{KCl}$ ), $0.2 \mathrm{mM}$ dNTPs, 2 $\mathrm{mM} \mathrm{MgCl}, 10 \mathrm{pM}$ primer, 1.0 Unit of Taq DNA polymerase and 25-50 ng genomic DNA. For standardization of annealing temperatures of SSR primers, gradient PCR was carried out in a gradient thermal cycler. Initial denaturation at $94^{\circ} \mathrm{C}$ for 5 min was followed by 35 cycles at $94^{\circ} \mathrm{C}$ for $1 \mathrm{~min}, 48-60^{\circ} \mathrm{C}$ for $1 \mathrm{~min}$ and $72^{\circ} \mathrm{C}$ for $2 \mathrm{~min}$. The final extension was carried out at $72{ }^{\circ} \mathrm{C}$ for $7 \mathrm{~min}$. For ISSR amplification products were run on $2 \%$ agarose and for microsatellites amplification $4 \%$ superfine agarose was used. The bands were then visualized under UV light and photographed.

\section{Molecular data analysis}

The prominent DNA bands that were amplified by a given primer were scored as present (1) or absent (0) for all of the samples that were studied. In order to determine the utility of these markers, number of amplicons per primers, percent polymorphism, polymorphic information content (PIC), effective multiplex ratio (EMR)/resolving power (Rp) and marker index $(\mathrm{MI})$ were calculated:

- Percent polymorphism was calculated as percentage of polymorphic loci from total loci obtained per primer.

- The polymorphism information content (PIC) value of individual primers were calculated based on the formula $\mathrm{PIC}=$ $2 \times F(1-F)$.
- Marker index, a product of information content, as measured by PIC, and effective multiplex ratio (EMR), the product of the fraction of polymorphic loci and the number of polymorphic loci for an individual assay, was calculated following Powell et al. (1996) and resolving power (RP) of each primer combination was calculated according to Prevost and Willkinson (1999).

The Jaccard's similarity index was calculated using NTSYS-pc version $2.02 \mathrm{e}$ package to compute pairwise Jaccard's similarity coefficients (Jaccard, 1908) and this similarity matrix was used in cluster analysis using an unweighted pair-group method with arithmetic averages (UPGMA) and sequential, agglomerative, hierarchical and nested (SAHN) clustering algorithm to obtain a dendrogram.

To judge the confidence of the group revealed in the dendrogram, bootstrap analysis was performed using the WINBOOT program with 1,000 replications.

The correlation of matrices obtained from SSR, ISSR and RAPD profiles was judged by two-way Mantel test (Mantel, 1967) using MxComp Module of NTSYSPC version 2.02e.

\section{Results and discussions}

Applications of molecular markers have opened up new insights on taxonomic analysis (Grilli-Caiola et al., 2004) in saffron. There are few articles that used molecular and biochemical approaches in an attempt to classify and clarify the systematic and phylogeny of this genus (Alavi-Kia et al., 2008; Frizzi et al., 2007; Grilli-Caiola et al., 2004; Keify and Beiki, 2012; Rubio-Moraga et al., 2009; Rubio-Moraga et al., 2010; Sik et al., 2008).

\section{RAPD analysis}

Amplified fragments from 128 RAPD primers varied in size from 200-1,500 bp. Fifteen primers were found polymorphic, with an average of 2.04 bands per primer. The respective values for overall genetic variability for PIC, Rp and MI across all the 31 clonal selections are given in Table 1 . Highest PIC value (0.46) was observed in OPB1 and most of the primers showed zero value for PIC. Average PIC value was 0.03. The MI values ranged from 0.0 to 1.6 with an average of 0.06 . Highest value (1.60) was scored with primers OPA14 and OPA17. RP ranged from 1.29 to 12.0 with an average of 3.97 per primer. Highest value (12.0) was scored with primers OPP6, OPV3 and OPA13. Allele number per locus varied from one to six (OPA13, OPP6, OPV3) and number of polymorphic bands range from 0 to 4 (OPA14, OPA17). Our study revealed that primer OPA14 shows $100 \%$ polymorphism by producing all four polymorphic bands, while primer OPA13, OPV3 and OPP6 produced the maximum number of bands, thus have a high marker index. Previously, in addition to morphological identification various biochemical and molecular markers have been used for genetic characterization of saffron genotypes (Keify and Beiki, 2012; Qadri et al., 2012). Moraga et al. (2009) found that RAPD markers could not distinguish the saffron genotypes at molecular level, while Qadri et al. (2012) found that RAPD markers have very good potential for studying genetic diversity in saffron. Caiola et al. (2004) found that amplification of seven Crocus species with 21 primers provided 217 repeatable and interpretable fragments, which are much higher than our findings. RAPD markers have been used for molecular association (Imran et al., 2008) and origin determination in saffron (Pardo et al., 2004). 
Table 1. Polymorphic profile of 128 RAPD primers across 31 selections of saffron

\begin{tabular}{|c|c|c|c|c|c|c|c|c|c|c|c|}
\hline Primer & NB & NPB & PIC & $\mathrm{RP}$ & MI & Primer & NB & NPB & PIC & $\mathrm{RP}$ & MI \\
\hline OPA1 & 3 & 0 & 0.00 & 6.00 & 0.00 & OPZ6 & 1 & 0 & 0.00 & 2.00 & 0.00 \\
\hline OPA2 & 2 & 0 & 0.00 & 4.00 & 0.00 & OPZ7 & 2 & 0 & 0.00 & 4.00 & 0.00 \\
\hline OPA3 & 3 & 0 & 0.00 & 6.00 & 0.00 & OPZ8 & 3 & 0 & 0.00 & 6.00 & 0.00 \\
\hline OPA4 & 4 & 0 & 0.00 & 8.00 & 0.00 & OPZ9 & 2 & 0 & 0.00 & 4.00 & 0.00 \\
\hline OPA5 & 3 & 0 & 0.00 & 6.00 & 0.00 & OPZ10 & 3 & 0 & 0.00 & 6.00 & 0.00 \\
\hline OPA7 & 3 & 0 & 0.00 & 6.00 & 0.00 & OPP1 & 4 & 0 & 0.00 & 8.00 & 0.00 \\
\hline OPA11 & 5 & 0 & 0.00 & 10.00 & 0.00 & OPP2 & 3 & 0 & 0.00 & 6.00 & 0.00 \\
\hline OPA 12 & 2 & 0 & 0.00 & 4.00 & 0.00 & OPP3 & 3 & 0 & 0.00 & 6.00 & 0.00 \\
\hline OPA13 & 6 & 0 & 0.00 & 12.00 & 0.00 & OPP4 & 5 & 0 & 0.00 & 10.00 & 0.00 \\
\hline OPA 14 & 4 & 4 & 0.40 & 5.16 & 1.60 & OPP5 & 2 & 0 & 0.00 & 4.00 & 0.00 \\
\hline OPA 15 & 1 & 1 & 0.35 & 1.55 & 0.35 & OPP6 & 6 & 0 & 0.00 & 12.00 & 0.00 \\
\hline OPA16 & 2 & 2 & 0.24 & 3.41 & 0.66 & OPP7 & 4 & 0 & 0.00 & 8.00 & 0.00 \\
\hline OPA17 & 4 & 4 & 0.40 & 5.16 & 1.60 & OPP8 & 1 & 0 & 0.00 & 2.00 & 0.00 \\
\hline OPA20 & 2 & 2 & 0.20 & 1.61 & 0.41 & OPP9 & 2 & 0 & 0.00 & 4.00 & 0.00 \\
\hline OPB1 & 1 & 1 & 0.46 & 1.29 & 0.46 & OPP10 & 4 & 0 & 0.00 & 8.00 & 0.00 \\
\hline OPB2 & 1 & 0 & 0.00 & 2.00 & 0.00 & OPO1 & 2 & 0 & 0.00 & 4.00 & 0.00 \\
\hline OPB3 & 1 & 0 & 0.00 & 2.00 & 0.00 & OPO2 & 1 & 0 & 0.00 & 2.00 & 0.00 \\
\hline OPB4 & 2 & 0 & 0.00 & 4.00 & 0.00 & OPO3 & 1 & 0 & 0.00 & 2.00 & 0.00 \\
\hline OPB5 & 1 & 0 & 0.00 & 2.00 & 0.00 & OPO4 & 1 & 0 & 0.00 & 2.00 & 0.00 \\
\hline OPB6 & 1 & 0 & 0.00 & 2.00 & 0.00 & OPO5 & 2 & 0 & 0.00 & 4.00 & 0.00 \\
\hline OPB7 & 1 & 0 & 0.00 & 2.00 & 0.00 & OPO6 & 1 & 0 & 0.00 & 2.00 & 0.00 \\
\hline OPB8 & 1 & 0 & 0.00 & 2.00 & 0.00 & OPO7 & 1 & 0 & 0.00 & 2.00 & 0.00 \\
\hline OPB9 & 1 & 0 & 0.00 & 2.00 & 0.00 & OPO8 & 1 & 0 & 0.00 & 2.00 & 0.00 \\
\hline OPB10 & 1 & 0 & 0.00 & 2.00 & 0.00 & OPO9 & 1 & 0 & 0.00 & 2.00 & 0.00 \\
\hline OPJ1 & 1 & 0 & 0.00 & 2.00 & 0.00 & OPO10 & 1 & 0 & 0.00 & 2.00 & 0.00 \\
\hline OPJ2 & 2 & 0 & 0.00 & 4.00 & 0.00 & OPS1 & 1 & 0 & 0.00 & 2.00 & 0.00 \\
\hline OPJ3 & 3 & 0 & 0.00 & 4.00 & 0.00 & OPS2 & 1 & 0 & 0.00 & 2.00 & 0.00 \\
\hline OPJ4 & 1 & 0 & 0.00 & 2.00 & 0.00 & OPS3 & 2 & 0 & 0.00 & 4.00 & 0.00 \\
\hline OPJ5 & 2 & 1 & 0.08 & 3.80 & 0.17 & OPS4 & 2 & 0 & 0.00 & 4.00 & 0.00 \\
\hline OPJ6 & 2 & 2 & 0.09 & 3.80 & 0.18 & OPS5 & 1 & 0 & 0.00 & 2.00 & 0.00 \\
\hline OPJ7 & 1 & 1 & 0.06 & 1.94 & 0.06 & OPM1 & 2 & 0 & 0.00 & 4.00 & 0.00 \\
\hline OPJ8 & 1 & 1 & 0.06 & 1.94 & 0.06 & OPM2 & 2 & 0 & 0.00 & 4.00 & 0.00 \\
\hline OPJ9 & 2 & 2 & 0.23 & 3.41 & 0.47 & OPM3 & 1 & 0 & 0.00 & 2.00 & 0.00 \\
\hline OPJ10 & 3 & 0 & 0.00 & 6.00 & 0.00 & OPM4 & 1 & 0 & 0.00 & 2.00 & 0.00 \\
\hline OPJ11 & 2 & 0 & 0.00 & 4.00 & 0.00 & OPM5 & 2 & 0 & 0.00 & 4.00 & 0.00 \\
\hline OPJ12 & 3 & 0 & 0.00 & 6.00 & 0.00 & OPL1 & 3 & 0 & 0.00 & 6.00 & 0.00 \\
\hline OPJ13 & 4 & 0 & 0.00 & 8.00 & 0.00 & OPL2 & 2 & 0 & 0.00 & 4.00 & 0.00 \\
\hline OPJ14 & 3 & 0 & 0.00 & 6.00 & 0.00 & OPL3 & 3 & 0 & 0.00 & 6.00 & 0.00 \\
\hline OPJ15 & 3 & 0 & 0.00 & 6.00 & 0.00 & OPL4 & 4 & 0 & 0.00 & 8.00 & 0.00 \\
\hline OPV1 & 5 & 0 & 0.00 & 10.00 & 0.00 & OPL5 & 3 & 0 & 0.00 & 6.00 & 0.00 \\
\hline OPV2 & 2 & 0 & 0.00 & 4.00 & 0.00 & OPL6 & 3 & 0 & 0.00 & 6.00 & 0.00 \\
\hline OPV3 & 6 & 0 & 0.00 & 12.00 & 0.00 & OPL7 & 2 & 0 & 0.00 & 4.00 & 0.00 \\
\hline OPV4 & 4 & 0 & 0.00 & 8.00 & 0.00 & OPL8 & 2 & 0 & 0.00 & 4.00 & 0.00 \\
\hline OPV5 & 1 & 1 & 0.22 & 1.74 & 0.22 & OPL9 & 2 & 0 & 0.00 & 4.00 & 0.00 \\
\hline OPV6 & 2 & 2 & 0.21 & 3.48 & 0.55 & OPL10 & 2 & 0 & 0.00 & 4.00 & 0.00 \\
\hline OPV7 & 3 & 0 & 0.00 & 6.00 & 0.00 & OPR1 & 1 & 0 & 0.00 & 2.00 & 0.00 \\
\hline OPV8 & 2 & 0 & 0.00 & 4.00 & 0.00 & OPR2 & 2 & 2 & 0.24 & 3.41 & 0.66 \\
\hline OPV9 & 1 & 1 & 0.38 & 1.48 & 0.38 & OPR3 & 4 & 0 & 0.00 & 8.00 & 0.00 \\
\hline OPV10 & 1 & 0 & 0.00 & 2.00 & 0.00 & OPR4 & 2 & 0 & 0.00 & 4.00 & 0.00 \\
\hline OPU1 & 1 & 0 & 0.00 & 2.00 & 0.00 & OPR5 & 1 & 0 & 0.00 & 2.00 & 0.00 \\
\hline OPU2 & 2 & 0 & 0.00 & 4.00 & 0.00 & OPR5 & 1 & 0 & 0.00 & 2.00 & 0.00 \\
\hline OPU3 & 1 & 0 & 0.00 & 2.00 & 0.00 & OPR6 & 1 & 0 & 0.00 & 4.00 & 0.00 \\
\hline OPU4 & 1 & 0 & 0.00 & 2.00 & 0.00 & OPR7 & 2 & 0 & 0.00 & 2.00 & 0.00 \\
\hline OPU5 & 1 & 0 & 0.00 & 2.00 & 0.00 & OPR8 & 1 & 0 & 0.00 & 2.00 & 0.00 \\
\hline OPU6 & 1 & 0 & 0.00 & 2.00 & 0.00 & OPR9 & 1 & 0 & 0.00 & 2.00 & 0.00 \\
\hline OPU7 & 1 & 0 & 0.00 & 2.00 & 0.00 & OPR10 & 1 & 0 & 0.00 & 2.00 & 0.00 \\
\hline OPU8 & 1 & 0 & 0.00 & 2.00 & 0.00 & OPT1 & 1 & 0 & 0.00 & 2.00 & 0.00 \\
\hline OPU9 & 1 & 0 & 0.00 & 2.00 & 0.00 & OPT2 & 1 & 0 & 0.00 & 2.00 & 0.00 \\
\hline OPU10 & 2 & 0 & 0.00 & 4.00 & 0.00 & OPT4 & 1 & 0 & 0.00 & 2.00 & 0.00 \\
\hline OPZ1 & 2 & 0 & 0.00 & 4.00 & 0.00 & OPT5 & 2 & 0 & 0.00 & 4.00 & 0.00 \\
\hline OPZ2 & 1 & 0 & 0.00 & 2.00 & 0.00 & OPC1 & 2 & 0 & 0.00 & 4.00 & 0.00 \\
\hline OPZ3 & 2 & 0 & 0.00 & 4.00 & 0.00 & OPC2 & 1 & 0 & 0.00 & 2.00 & 0.00 \\
\hline OPZ4 & 2 & 0 & 0.00 & 4.00 & 0.00 & OPC3 & 2 & 0 & 0.00 & 4.00 & 0.00 \\
\hline OPZ5 & 1 & 0 & 0.00 & 2.00 & 0.00 & OPC4 & 2 & 0 & 0.00 & 4.00 & 0.00 \\
\hline
\end{tabular}

NB- Number of bands; NBP- Number of polymorphic bands; PIC- Polymorphic information content; RP- Resolving power; MI- Marker index 


\section{SSR analysis}

Thirty one SSR primers resulted in number of amplified fragments which varied in size from $160-400 \mathrm{bp}$. None of the primers was found polymorphic. Bands per primer range from 1 to 2 , with an average of 1.1 bands per primer. Since all the primers were found monomorphic across the 31 selections, thus all SSR primers show zero values for PIC and MI. Rp value range from 2-4 (CSMIC19, CSMIC43 and CSMIC51). Allele number per locus varied from 1 to 2 (CSMIC19, CSMIC43 and CSMIC51) with an average of 1.1 alleles per loci (Table 2), which is very low. Our findings show that SSR primers, although considered very good markers with high reproducibility, could not identify any polymorphism among the selected clones. Hence, there is need to develop more SSR markers for scanning more of the saffron genome. Moraga et al. (2009) also found that existing SSR markers could not distinguish saffron genotypes. Microsatellite markers are useful for genetic diversity analysis studies at varietal, species and genus level, due to their sequence conservation at flanking regions (Hamza et al., 2004). Also there is need to exploit functional genomic variation in saffron so that EST-SSR markers could be developed for identifying and exploiting variation in these saffron selection. The major constraint of using SSR markers from genomic libraries is the high development cost and the effort required to obtain working primers for a given study species. This has restricted their use to only a few of the agriculturally important crops. Recently, a new alternative source of SSRs development from genomic and expressed sequence tag (EST) databases has been utilized (Ozkan et al., 2013). With the availability of a large number of ESTs and other DNA sequence data, development of EST-based SSR markers through data mining has become a fast, efficient and relatively inexpensive method compared with the development of genomic SSRs (Gupta et al., 2003).

\section{ISSR analysis}

Amplified fragments from 50 ISSR primers varied in size from 150-900 bp. Only five out of fifteen primers were found polymorphic, with an average of 1.06 bands per primer. The respective values for overall genetic variability for PIC, Rp and MI across all the 31 clonal selections are given in Table 3. Highest PIC value (0.32) was observed for ISCS8 and ISCS24. The average PIC value was 0.018 . The MI values ranged from 0.0 to 0.65 with an average of 0.04 . Highest value $(0.65)$ was scored with primers ISCS8 and ISCS24. RP ranged from 1.93 to 3.81, with an average of 2.07 per primer. Highest value (3.81) was scored with the primer ISCS1 and the lowest value (1.94) for the primers ISCS12 and ISCS18. Allele number per locus varied from 1 to 2 (ISCS1, ISCS8, ISCS24) and number of polymorphic bands range from 0 to 2 (ISCS8 and ISCS24). Hence our findings suggest that ISSR markers ISCS1, ISCS8, ISCS24 have desirable values for all primer parameters (PIC, Rp and MI), therefore they can have potential for studying genetic diversity in saffron. Our study revealed that ISSR markers can be used for studying the genetic diversity in saffron, but should be used along with other markers and more ISSR primers with higher number of selections. Moraga et al. (2009) found that ISSR markers could not reveal any polymorphism in saffron. ISSRs exhibit the specificity of

Table 2. Genetic diversity profile of 31 SSR primers across 31 selections of saffron

\begin{tabular}{|c|c|c|c|c|c|c|}
\hline Primer & Forward Primer sequence 5'-3' & Reverse Primer sequence 5'-3' & Amplicon size bp & PIC & $\mathrm{RP}$ & MI \\
\hline CSMIC7 & GAATCACCACCTGAATTGTGAG & AAGAGGTCGAAGAAGGGAAAAC & 280 & 0.0 & 2.0 & 0.0 \\
\hline CSMIC8 & TCTTGGAATGGTTAGAGCGTGT & ACCAGCAATCTTTGGAACAGTC & 300 & 0.0 & 2.0 & 0.0 \\
\hline CSMIC9 & ACTGAAAGAAAGGGGAGAAAGG & TATATCGAATGGAGGTTCCGTC & 230 & 0.0 & 2.0 & 0.0 \\
\hline CSMIC10 & AATCACACACAACATGGTCGTT & TGTTTAACCCAGCTAGCAGAAT & 300 & 0.0 & 2.0 & 0.0 \\
\hline CSMIC19 & GGCCTAGCTAGCAGAATCACAA & AGCTAGCAGAATCACACTCTT & $300 \& 400$ & 0.0 & 4.0 & 0.0 \\
\hline CSMIC21 & CTCGCTAGCCGAATCACAACT & TGTGAGAGCACACGGTGT & 200 & 0.0 & 2.0 & 0.0 \\
\hline CSMIC26 & ATCACTCATAАСТСТССАTGA & AGCTAGCAGATCACATAGGT & 350 & 0.0 & 2.0 & 0.0 \\
\hline CSMIC27 & TGGATATACGTAATCCAGACT & ATAATTCCTGAGGTGAATT & 300 & 0.0 & 2.0 & 0.0 \\
\hline CSMIC28 & TAAGGCCATGCTAGCAGAAT & AGCAGTAATTCGTAGCGACA & 310 & 0.0 & 2.0 & 0.0 \\
\hline CSMIC30 & GCAGAATCACACATGGTTACAA & AGTGACACGACACTCACTAT & 260 & 0.0 & 2.0 & 0.0 \\
\hline CSMIC38 & GTCTAAGGCCTAGCTAGCAGA & GTTATCAAATGTTGGCCCACT & 300 & 0.0 & 2.0 & 0.0 \\
\hline CSMIC39 & GCTAGCAGAATCACTACTTGA & AATGTTGGCCCACTCACACT & 350 & 0.0 & 2.0 & 0.0 \\
\hline CSMIC43 & GCAGAATCACTACTTGAAGACA & TGAGATGGATATATTCTCTGA & $250 \& 350$ & 0.0 & 4.0 & 0.0 \\
\hline CSMIC544 & CAGTGCTTCGGCTGAATGTGAA & ACTGCTGGACGGTGCAACTT & 200 & 0.0 & 2.0 & 0.0 \\
\hline CSMIC45 & CCGCCTAGCTAGCAGAATCACA & GATAAGACCTGCAACTTCAACT & 160 & 0.0 & 2.0 & 0.0 \\
\hline CSMIC46 & GTACAGTGCTGAAGAGGAGGA & TGGATACGCTGCACGTATCTCA & 220 & 0.0 & 2.0 & 0.0 \\
\hline CSMIC47 & ACCAGGTCAGTTGATGCCTCAT & CAGTGTAGCTACTTAGACAGT & 250 & 0.0 & 2.0 & 0.0 \\
\hline CSMIC48 & GCGAGCGAAATCACAATCTCGA & GCGAGCGAAATCACAATCTCGA & 250 & 0.0 & 2.0 & 0.0 \\
\hline CSMIC49 & ACTAGTTCACTCATCCGTTA & TGAATCGAATGGGTAGGGAAT & 200 & 0.0 & 2.0 & 0.0 \\
\hline CSMIC50 & TAACCTCGTCGGAGCGGTGGA & GGAGCAACAATGGCGGTGGAA & 240 & 0.0 & 2.0 & 0.0 \\
\hline CSMIC51 & GACGGGTAGTAGAAAGTTCTTCA & CGAATGGGTCTCCAAACCCT & $250 \& 300$ & 0.0 & 4.0 & 0.0 \\
\hline CSMIC53 & GCAGAATCACTGCTGGACGGGT & CAGTGCTTCGGCTGAATGTGAA & 220 & 0.0 & 2.0 & 0.0 \\
\hline CSMIC54 & AGCAGCAGAGAAGTAAGACAGT & TCAАСТTСССААССАСТTTGA & 160 & 0.0 & 2.0 & 0.0 \\
\hline CSMIC55 & AGCAACAGAGGCACACATTCA & AGCTGTCAGTCCAATCATCAAC & 270 & 0.0 & 2.0 & 0.0 \\
\hline CSMIC56 & CTTATTGGATACGCTGCA & TAAGCCTAGCTAGCAGAA & 260 & 0.0 & 2.0 & 0.0 \\
\hline CSMIC57 & GTAACCTGCTCCAGTGCTA & TAAGGCCTAGCTAGCAGAATCT & 320 & 0.0 & 2.0 & 0.0 \\
\hline CSMIC58 & TCGTCATGGTCGTCGCTACTA & AGCCTAGCTAGCAGATCATAGA & 260 & 0.0 & 2.0 & 0.0 \\
\hline CSMIC59 & GAATATTGTTGATGAGGCCGGA & AAGAGAGATATTAAATAAGTCGCA & 200 & 0.0 & 2.0 & 0.0 \\
\hline CSMIC60 & CATCGGCCTGAATGCCGT & GGGAAGTTCAAATCCCACTA & 200 & 0.0 & 2.0 & 0.0 \\
\hline CSMIC61 & TTCAAGTGCTTATTGGTCCA & CATGTTCAATGCTTCATCAAGT & 318 & 0.0 & 2.0 & 0.0 \\
\hline CSMIC62 & CCAATCTGAGGACGGGCT & AGAAGCGTGATGAAGTGA & 350 & 0.0 & 2.0 & 0.0 \\
\hline
\end{tabular}

NB- Number of bands; NBP- Number of polymorphic bands; PIC- Polymorphic information content; RP- Resolving power; MI- Marker index 
microsatellite markers, but need no sequence information for primer synthesis enjoying the advantage of random markers (Joshi et al., 2000). ISSR markers usually show high polymorphism (Kojima et al., 1998) although the level of polymorphism has been shown to vary with the detection method used. Like RAPDs, reproducibility, dominant inheritance and homology of co-migrating amplification products are the main limitations of ISSRs.

Two-way Mantel test (Mantel, 1967) was done between the ISSR and RAPD data matrices. The correlation coefficient was estimated to be 0.33 between the matrices generated by ISSR and RAPD markers using the Mantel Test ( $\mathrm{t} 2.43$, P $0.99)$. Since SSR markers produce invariant similarity matrix due to monomorphic data hence could not be used for determining correlation through Mantel test.

\section{Genetic relationship}

In order to find out the genetic relationship between different saffron selections, SSR, ISSR and RAPD data sets were combined together and this general view data was used for

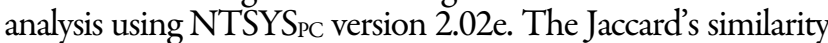
coefficient ranged from 0.94 to 1.00 with an average of 0.98 among all the 31 selections used (Table 4). Minimum similarity value (0.94) was observed between CITH-S-107 and PAM-S-116 selections. The genetic relationship between the accessions was clearly depicted in the dendrogram which was

Table 3. Polymorphic profile of 50 ISSR primers across 31 selections of saffron

\begin{tabular}{|c|c|c|c|c|c|c|}
\hline Primer & Primer Sequence 5'-3' & NB & NPB & PIC & $\mathrm{RP}$ & MI \\
\hline ISCS1 & ТССТССТССТССТССТССС & 2 & 1 & 0.17 & 3.81 & 0.35 \\
\hline ISCS2 & GATGATGATGATGATGATG & 1 & 0 & 0.00 & 2.00 & 0.00 \\
\hline ISCS3 & СТТСТТстТстТСтТстТстТс & 1 & 0 & 0.00 & 2.00 & 0.00 \\
\hline ISCS4 & TGGTGGTGGTGGTGGTGGC & 1 & 0 & 0.00 & 2.00 & 0.00 \\
\hline ISCS5 & GTGTGTGTGTGTGTGTGTG & 1 & 0 & 0.00 & 2.00 & 0.00 \\
\hline ISCS6 & GAGAGAGAGAGAGAGAG & 1 & 0 & 0.00 & 2.00 & 0.00 \\
\hline ISCS7 & ТСТСТСТСТСТСТСТСТСС & 1 & 0 & 0.00 & 2.00 & 0.00 \\
\hline ISCS8 & ТСТТСТТСТТСТТСТТСТТСТТСТТСТА & 2 & 2 & 0.32 & 3.03 & 0.65 \\
\hline ISCS9 & АTCATCATCATCATCATCATCATCATCATCG & 1 & 0 & 0.00 & 2.00 & 0.00 \\
\hline ISCS10 & ACACACACACACACACC & 1 & 0 & 0.00 & 2.00 & 0.00 \\
\hline ISCS11 & СТСТСТСТСТСТСТСТТ & 1 & 0 & 0.00 & 2.00 & 0.00 \\
\hline ISCS12 & TTGTTGTTGTTGTTGTTGC & 1 & 1 & 0.06 & 1.94 & 0.06 \\
\hline ISCS13 & TATTATTATTATTATTATTATTATG & 1 & 0 & 0.00 & 2.00 & 0.00 \\
\hline ISCS14 & AGTGAGTGAGTGAGTGAGTGA & 1 & 0 & 0.00 & 2.00 & 0.00 \\
\hline ISCS15 & ТАТСТАТСТАТСТАТСТАТСТАТСТ & 1 & 0 & 0.00 & 2.00 & 0.00 \\
\hline ISCS16 & HBHGAGGAGGAGGAGGAG & 1 & 0 & 0.00 & 2.00 & 0.00 \\
\hline ISCS17 & DBDBCACCACCACCACCAC & 1 & 0 & 0.00 & 2.00 & 0.00 \\
\hline ISCS18 & DBDBCCACCACCACCACCA & 1 & 1 & 0.06 & 1.94 & 0.06 \\
\hline ISCS19 & HVHGTGGTGGTGGTGGTG & 1 & 0 & 0.00 & 2.00 & 0.00 \\
\hline ISCS20 & DHBCGACGACGACGACGA & 1 & 0 & 0.00 & 2.00 & 0.00 \\
\hline ISCS21 & BDBACAACAACAACAACA & 1 & 0 & 0.00 & 2.00 & 0.00 \\
\hline ISCS22 & HBBGAAGAAGAAGAAGAA & 1 & 0 & 0.00 & 2.00 & 0.00 \\
\hline ISCS23 & HBDBGACCGACCGACCGACC & 1 & 0 & 0.00 & 2.00 & 0.00 \\
\hline ISCS24 & HBVBGATAGATAGATAGATA & 2 & 2 & 0.32 & 3.03 & 0.65 \\
\hline ISCS25 & HBVCGATCGATCGATCGAT & 1 & 0 & 0.00 & 2.00 & 0.00 \\
\hline ISCS26 & GTGTGTGTGTGTGTGTYG & 1 & 0 & 0.00 & 2.00 & 0.00 \\
\hline ISCS27 & TCTCTCTСТСТСТСТСRA & 1 & 0 & 0.00 & 2.00 & 0.00 \\
\hline ISCS28 & TCTCTCTCTCTCTCTCRT & 1 & 0 & 0.00 & 2.00 & 0.00 \\
\hline ISCS29 & TCTCTCTCTCTCTCTCRG & 1 & 0 & 0.00 & 2.00 & 0.00 \\
\hline ISCS30 & ACACACACACACACACYT & 1 & 0 & 0.00 & 2.00 & 0.00 \\
\hline ISCS31 & ACACACACACACACACYA & 1 & 0 & 0.00 & 2.00 & 0.00 \\
\hline ISCS32 & ACACACACACACACACYG & 1 & 0 & 0.00 & 2.00 & 0.00 \\
\hline ISCS33 & TGTGTGTGTGTGTGTGRT & 1 & 0 & 0.00 & 2.00 & 0.00 \\
\hline ISCS34 & TGTGTGTGTGTGTGTGRC & 1 & 0 & 0.00 & 2.00 & 0.00 \\
\hline ISCS35 & TGTGTGTGTGTGTGTGRA & 1 & 0 & 0.00 & 2.00 & 0.00 \\
\hline ISCS36 & ACСАССАССАССАССАСС & 1 & 0 & 0.00 & 2.00 & 0.00 \\
\hline ISCS37 & AGCAGCAGCAGCAGCAGC & 1 & 0 & 0.00 & 2.00 & 0.00 \\
\hline ISCS38 & GTGTGTGTGTGTGTGTYC & 1 & 0 & 0.00 & 2.00 & 0.00 \\
\hline ISCS39 & ATGATGATGATGATGATG & 1 & 0 & 0.00 & 2.00 & 0.00 \\
\hline ISCS40 & CCGCCGCCGCCGCCGCCG & 1 & 0 & 0.00 & 2.00 & 0.00 \\
\hline ISCS41 & СТССТССТССТССТССТС & 1 & 0 & 0.00 & 2.00 & 0.00 \\
\hline ISCS42 & GGCGGCGGCGGCGGCGGC & 1 & 0 & 0.00 & 2.00 & 0.00 \\
\hline ISCS43 & GAAGAAGAAGAAGAAGAA & 1 & 0 & 0.00 & 2.00 & 0.00 \\
\hline ISCS44 & GTTGTTGTTGTTGTTGTT & 1 & 0 & 0.00 & 2.00 & 0.00 \\
\hline ISCS45 & TGCTGCTGCTGCTGCTGC & 1 & 0 & 0.00 & 2.00 & 0.00 \\
\hline ISCS46 & GTGTGTGTGTGTGTGTYA & 1 & 0 & 0.00 & 2.00 & 0.00 \\
\hline ISCS47 & CACACACACACACACARG & 1 & 0 & 0.00 & 2.00 & 0.00 \\
\hline ISCS48 & GACAGACAGACAGACA & 1 & 0 & 0.00 & 2.00 & 0.00 \\
\hline ISCS49 & СССТСССТСССТСССТ & 1 & 0 & 0.00 & 2.00 & 0.00 \\
\hline ISCS50 & CACACACACACACACARC & 1 & 0 & 0.00 & 2.00 & 0.00 \\
\hline
\end{tabular}

NB- Number of bands; NBP- Number of polymorphic bands; PIC- Polymorphic information content; RP- Resolving power; MI- Marker index 
86

constructed from the DNA profile. The dendrogram showed that all the selections are closely related with very low variability (Fig. 1).

The genetic closeness among the selections can be explained by the high degree of commonness in these selections, due to lack of sexual reproduction and geographically closed locations. All the 31 selections formed five main clusters with some degree of sub-clustering within. Cluster I, II, III, IV and V represent four selections (CITH-S125, CITH-S-115, PAM-S-13 and PAM-S-101), 15 (CITHS-124, PAM-S-3, PAM-S-106, CITH-S-122, CITH-S-114, PAM-S-102, PAM-S-111, BUS-S-76, CITH-S-12, CITH-S113, CITH-S-112, CITH-S-105, PAM-S-11, PAM-S-108 and CITH-S-103), 5 (CITH-S-121, CITH-S-118, CITH-S120, CITH-S-104 and CITH-S-117), 3 (BUD-S-110, CITHS-10 and CITH-S-119) and 3 selections (CITH-S-123, CITH-S-43 and CITH-S-107) respectively. Cluster I shows average similarity of $98.7 \%, 98 \%, 97.8 \%$ and $98 \%$ with cluster II, III, IV and V respectively. However, within the cluster I the average similarity was $99.4 \%$ and within cluster II, III, IV and V it was $99.0 \%, 98.7 \%, 98 \%$ and $98.6 \%$, respectively. Cluster II shows average similarity coefficient of $98.4 \%$ with cluster III, IV and V; Cluster III shows $97.8 \%$ and $97.9 \%$ of average similarity with cluster IV and V respectively, and cluster IV shows $97.3 \%$ similarity with cluster V. Never the less, the minimum similarity (97.3\%) observed between clusters IV and $\mathrm{V}$ is very high; this revealed that the selections are closely related at molecular level. Selection PAM-S-116 did not form part of any cluster and form separate co-ordinate in PCO analysis. The principal coordinate analysis $(\mathrm{PCO})$ showed that the first three axes accounted for $98.5 \%$ (97.7, 0.4 and 0.32 by Ist, 2nd and 3 rd co-ordinate respectively) of total variation. The grouping shown in dendrogram was at par with that shown in 3D scatter (Fig. 2). The results obtained using 128 RAPD, 50 ISSR and 31 SSR primers that yield a total of 34 polymorphic loci, produced a fingerprint that could be used for diversity analysis and identification of diverse selections among the selected ones (Fig. 3). Also, association of molecular marker data can be done with morphological parameters. Very little study has been done on association of molecular data with morphological or yield related characters. Studies in relation to genetic variability and divergence in saffron have been studied (Anonymous, 2006).
Genetic variation and heritability of agro-morphological and photochemical traits in Iranian saffron populations have been studied, and populations were found significantly different for most evaluated traits, like leaf number per plant, leaf length, flower number per plot, dry stigma weight per plot, spathe number and the content of crocins, picrocrocin and safranal (Baghalian et al., 2010). Moraga et al. (2009) found that saffron is a monomorphic species as revealed by RAPD, ISSR and microsatellite analyses. Pardo et al. (2004) investigated the distinction and variability of Crocus sativus from several geographic areas (Italy, Iran, Greece and Spain) using molecular markers and dry stigmas as plant material. Zubor et al. (2004) used AFLP markers to study the genetic diversity among different saffron species and found the close relationship between these species. AFLP has been found an effective tool for identifying genetic variability in saffron (Crocus sativus $\mathrm{L}$.) of different origin (Siracusa et al., 2012). Reterotransposons have also been used for studying the genetic diversity among different saffron species, and genetic variation was observed within and between species, whereas in some cases variation was found among ecotypes of the same species from different geographical regions (Alavi-Kia et al., 2008). Use of molecular markers as a tool for identification of variability among different saffron clones is an important area for improvement of this crop through breeding. Sequencing of corm cDNAs at different developmental stages would increase our knowledge about the physiological processes occurring in this organ. Little work has been done so for in these areas, in regard to the development of gene expression in saffron corm at different time intervals (Ortí et al., 2004). Different ESTs with respect to corm development, signal perception and transduction, defense against pathogen and stress, metabolism, development and gene regulation, cell organization, protein metabolism, transport etc. have been identified. EST data-base from saffron stigmas has been produced (D'Agostino et al., 2007), and this will be very useful for detecting the level of expression of different components in saffron genotypes. Furthermore, this data-base will be very useful for designing functional markers (EST-SSR) which can be used for identifying the variation among different saffron selections at transcriptional level. Since present markers did not reveal any significant polymorphism at

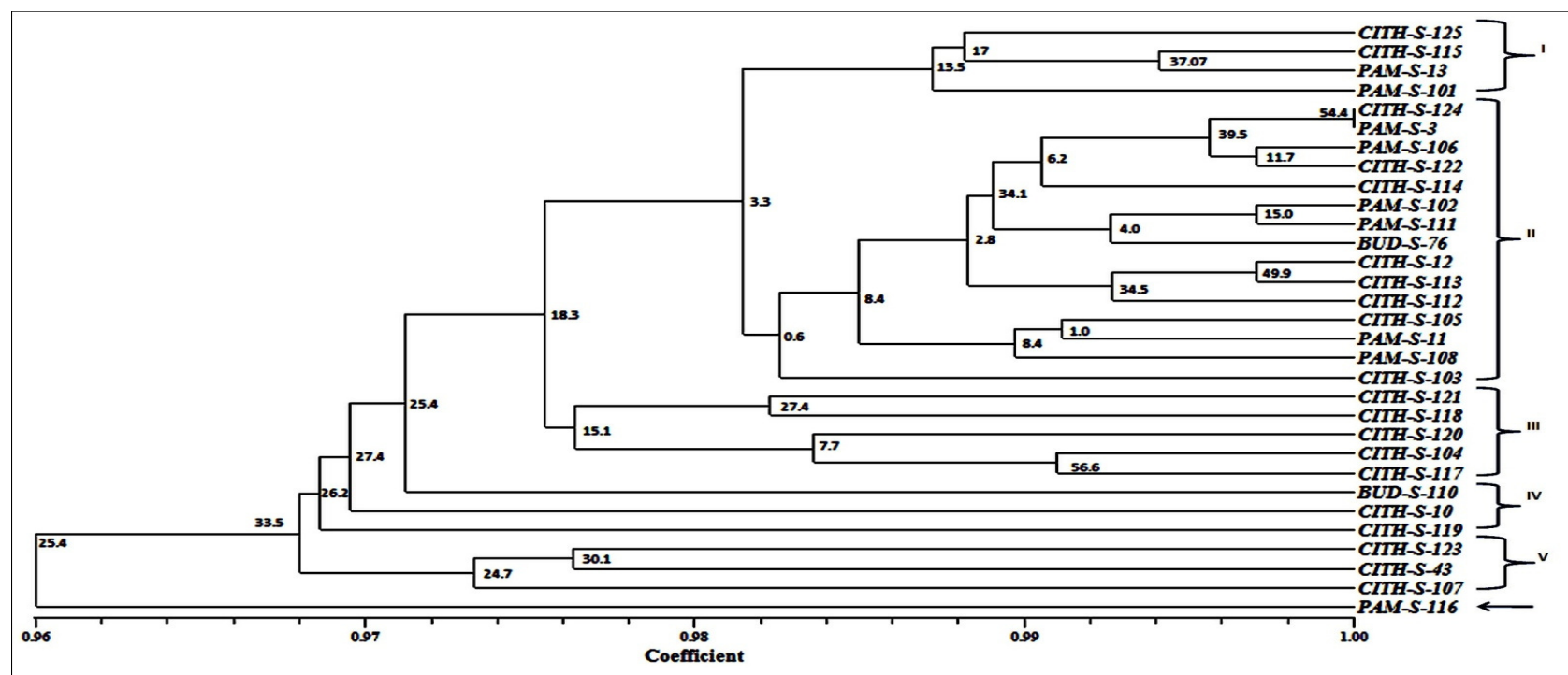

Fig. 1. UPGMA dendrogram showing clustering pattern of saffron selections. The bootstrap values are given on the nodes 


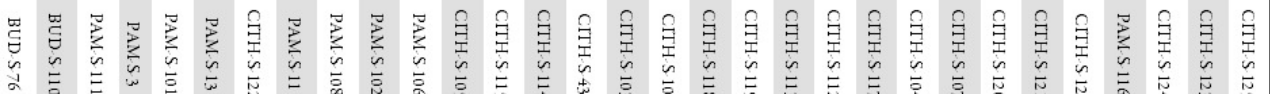

客 \&

宽

琣

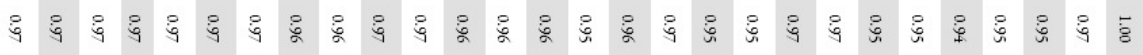

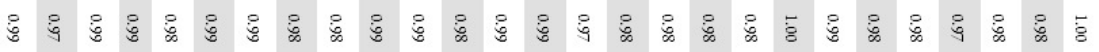

近 \&

离

离点

争

三

$\approx$ 年

空

高突

审

$\hat{\bar{c}}$ 冢

安

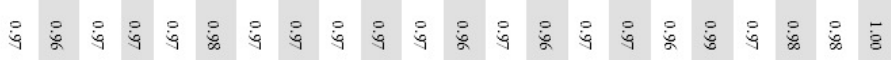

突恶

安

进

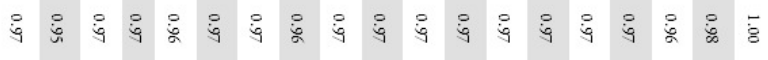

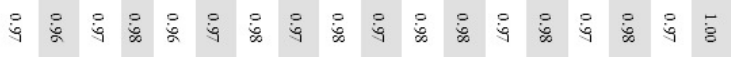

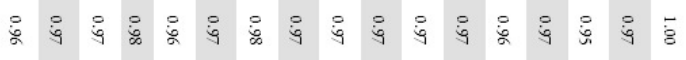

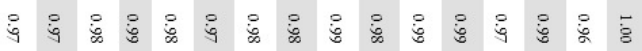

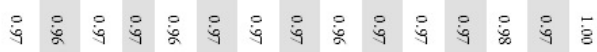

安

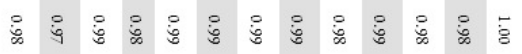

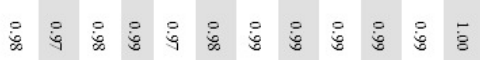

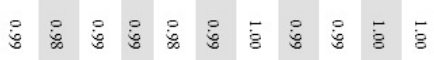

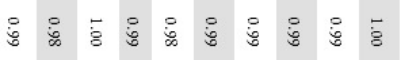

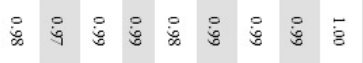

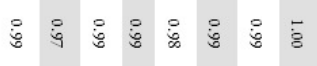

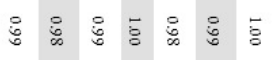

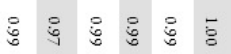

: $:$

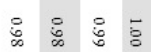

: :

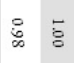

$\overline{5}$ 
88

genetic level between different saffron selections, there is the need to develop more number of markers, particularity SSR markers, which can be used for high density profiling. Sequencing of saffron genome can also play an important role in designing different types of quality molecular markers. But no serious efforts have been made in sequencing saffron genome yet.

Our study revealed that selections chosen for this study showed variation at molecular level, which can further be deciphered by using more number of molecular markers for high throughput scanning and high density profiling of saffron genome. Further study needs to be done to identify divergent selections with respect to different traits for improvement of this crop.

\section{Conclusions}

To slow down or stop geographical decline in saffron cultivation and, rather, to achieve an appreciable expansion of saffron-producing areas, a substantial increase in productivity by selecting superior clones is the need of the hour. The creation of new cultivars based on the identification of clones with higher apocarotenoid biosynthetic potential will facilitate this process. There is an urgent necessity to study the genetic and selection potential of various populations of saffron in Kashmir, as well as the populations in each region separately. Present study screened 31 morphologically distinct saffron clones and identified clones with better quality stigma, higher yield and maximum apocarotenoid biosynthetic potential. Although our study revealed that these clones selected are not divergent at molecular level, however, these can be mass multiplied under Kashmir conditions for saffron crop improvement and economic development.

\section{Acknowledgements}

Authors are thankful to Department of Biotechnology, University of Kashmir, Srinagar (J\&K, India) and Central Institute of Temperate Horticulture (ICAR), Srinagar

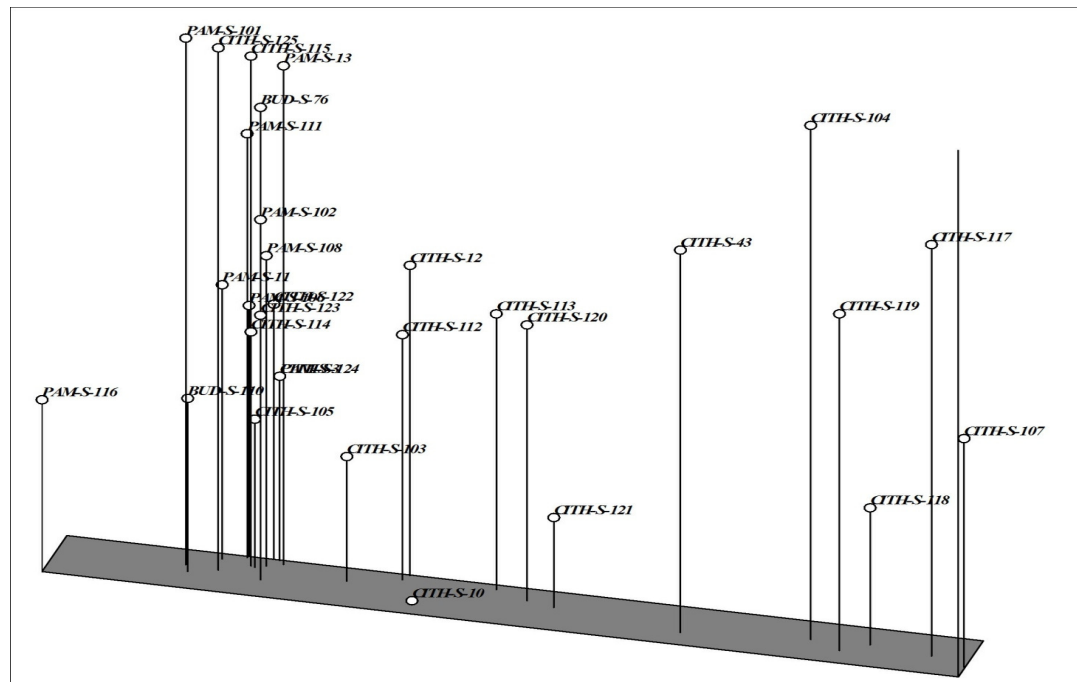

Fig. 2. Three dimensional PCO (principal co-ordinate analysis) scaling of 31 saffron genotypes using RAPD, ISSR and SSR markers

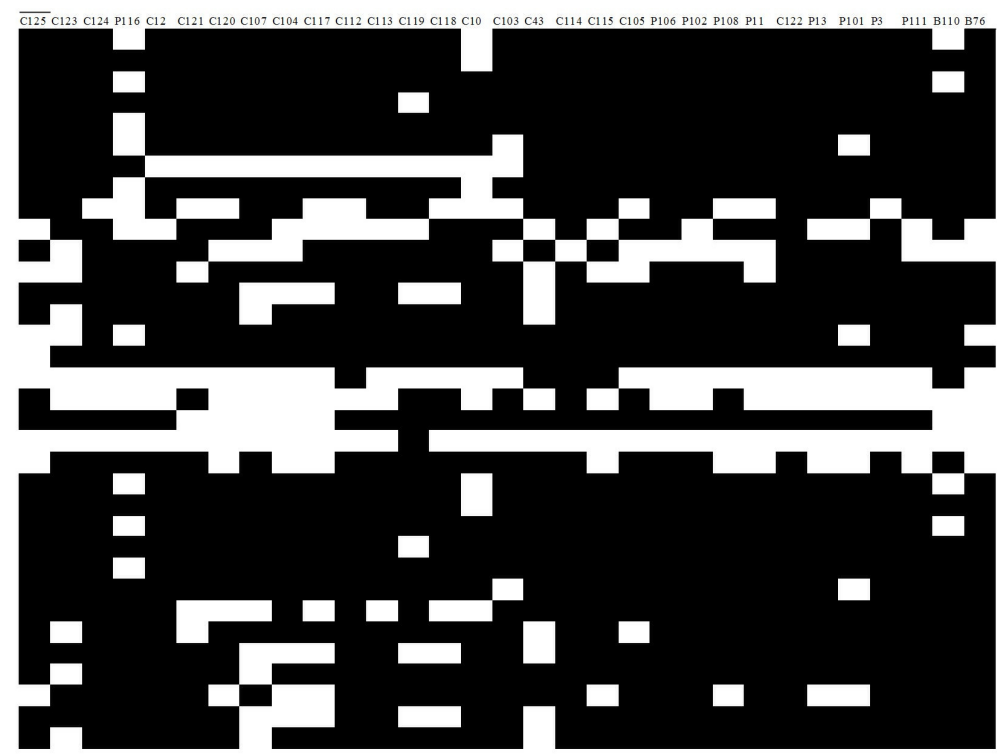

Fig. 3. Fingerprint derived from polymorphic markers representing level of polymorphism between 31 saffron selections (C: CITH; P: PAM and B: BUD) 
(J\&K, India) for extended research and financial support.

\section{References}

Alavi-Kia SS, Mohammadi SA, Aharizad S, Moghadam M (2008). Analysis of genetic diversity and phylogenetic relationships in crocus genus of Iran using inter-retrotransposon amplified polymorphism. Biotechnol Eq 22:795-800.

Anonymous (2006). Studies in relation to genetic variability and divergence in saffron (Crocus sativus L.) SKUAST(K), Srinagar, $\mathrm{J} \& \mathrm{~K}$, India.

Baghalian K, Shabani Sheshtamand M, Jamshidi AH (2010). Genetic variation and heritability of agro-morphological and phytochemical traits in Iranian saffron (Crocus sativus L.) populations. Industrial Crops and Products 31:401-406.

Caiola MG (2004). Saffron reproductive biology. Acta Hort 650:2537.

D’Agostino N, Pizzichini D, Chiusano ML, Giuliano G (2007). An EST database from saffron stigmas. BMC Plant Biol 7:53-53.

Frizzi G, Miranda M, Pantani C, Tammaro F (2007). Allozyme differentiation in four species of the Crocus cartwrightianus group and in cultivated saffron (Crocus sativus). Biochem Syst Ecol 35:859-868.

Gresta F, Lombardo GM, Siracusa L, Ruberto G (2008). Effect of mother corm dimension and sowing time on stigma yield, daughter corms and qualitative aspects of saffron (Crocus sativus L.) in a Mediterranean environment. J Sci Food Agr 88:11441150.

Grilli-Caiola M, Canini A (2004). Ultrastructure of chromoplasts and other plastids in Crocus sativus L. (Iridiaceae). Plant Biosyst 138:43.52.

Gupta PK, Rustgi S, Sharma S, Singh R, Kumar N, Balyan HS (2003). Transferable EST-SSR markers for the study of polymorphism and genetic diversity in bread wheat. Mol Genet Genomics 270:315-323.

Hamza S, Hamida WB, Rebai A, Harrabi M (2004). SSR based genetic diversity among Tunisian Barley and relationship with morphological traits. Euphytica 135:107-118.

Imran S, Khan MA, Lone AA, Nehvi FA (2008). Biotechnological interventions in saffron. Book chapter in Saffron production in Jammu and Kashmir, 67-86 p.

Jaccard P (1908). Nouvelles recherches sur la distribution florale. Bull Soc Vaud Sci Nat 44:223-270.

Joshi SP, Gupta VS, Aggarwal RK, Ranjekar PK, Brar DS (2000). Genetic diversity and phylogenetic relationship as revealed by intersimple sequence repeat (ISSR) polymorphism in the genus Oryza. Theor Appl Genet 100:1311-1320.

Kanakis CD, Daferera DJ, Tarantilis PA, Polissiou MG (2004). Qualitative determination of volatile compounds and quantitative evaluation of safranal and 4-hydroxy-2, 6, 6trimethyl-1-cyclohexene-1-carboxaldehyde (HTCC) in Greek saffron. J Agr Food Chem 52:4515-4521.

Keify F, Beiki AH (2012). Exploitation of random amplified polymorphic DNA (RAPD) and sequence-related amplified polymorphism (SRAP) markers for genetic diversity of saffron collection. Journal of Medicinal Plants Research 6(14):2761-
2768.

Mantel N (1967). The detection of disease clustering and a generalized regression approach. Cancer Res 27:209-220.

Moraga AR, Rambla JL, Ahrazem O, Granell A, Gomez-Gomez L (2009). Metabolite and target transcript analyses during Crocus sativus stigma development. Phytochemistry 70:1009-1016.

Negbi M (1999). Saffron cultivation: past, present and future prospects. In: Negbi M, Ed. Saffron: Crocus sativus L. Australia: Harwood Academic 1-15.

Orti MA, Gomez LG, Rubio A, Escribano J (2004). Development and gene expression in saffron corms. Acta Hort 650:35-38.

Ozkan H, Sik L, Erol O, Tanyolac MB (2013). Development of Simple Sequence Repeat (SSR) markers in saffron. In: Abstracts book of the International conference of plant and animal genome, San Diega CA, 12-13 p.

Pardo J, Fernandez JA, Gomez LG (2004). Development of molecular markers for origin determination in saffron. Acta Hort (ISHS) 650:95-98.

Powell W, Morgante M, Andre C, Hanafey M, Vogel J, Tingey S, Rafalsky A (1996). The comparison of RFLP, RAPD, AFLP and SSR (microsatellite) markers for germplasm analysis. Mol Breed 2:225-238.

Prevost A, Wilkinson MJ (1999). A new system of comparing PCR primers applied to ISSR fingerprinting of potato cultivars. Theor Appl Genet 98:107-112.

Qadri H, Sharma PC, Qureshi A, Singh SP, Nehvi FA (2012). DNA Fingerprinting of Saffron (Crocus sativus L.) by RAPD. Vegetos: An International Journal of Plant Research 25(1):194-197.

Rubio-Moraga A, Castillo-Lopez R, Gomez-Gomez L, Ahrazem O (2009). Saffron is a monomorphic species as revealed by RAPD, ISSR and microsatellite analyses. BMC Res Notes 2:189.

Rubio-Moraga A, Trapero-Mozos A, Gomez-Gomez L, Ahrazem O (2010). Inter simple sequence repeats markers for molecular characterization of Crocus cartwrightianus cv. Albus. Indus. Crops Prod 32:147-151.

Sik L, Candan F, Soya S, Karamenderes C, Kesercioglu T, Tanyyolc B (2008). Genetic variation among Crocus l. species from western Turkey as revealed by RAPD and ISSR marker. J Appl Biol Sci 2:73-78.

Siracusa L, Gresta F, Avola G, Albertini E, Raggi L, Marconi G, Lombardo GM, Ruberto G (2012). Agronomic, chemical and genetic variability of saffron (Crocus sativus $\mathrm{L}$.) of different origin by LC-UV-vis-DAD and AFLP analyses. Genet Resour Crop Evol DOI 10.1007/s10722-012-9868-9.

Yap IP, Nelson RJ (1996). Winboot: A program for performing bootstrap analysis of binary data to determine the confidence level. IRRI Discuss Paper Ser. 14, IRRI, Manila, Philippines.

Zubor AA, Suranyi G, Gyori Z, Borbely G, Prokisch J (2004). Molecular biological approach of the systematics of Crocus sativus L. and its allies. In: Abdullaev F (Ed). First international symposium on saffron biology and biotechnology, 85-93 p. 